\title{
Bone Marrow Derived Mesenchymal Stem Cells Are Recruited into Injured Pancreas and Contribute to Amelioration of the Chronic Pancreatitis in Rats
}

\author{
Hong Bin Liu \\ Department of Pharmacology, Tianjin Institute of Acute Abdominal Diseases, \\ Nankai Clinical College of Tianjin Medical University,
}

China

\section{Introduction}

Chronic pancreatitis is characterized by destruction of pancreatic parenchyma, inflammatory cell infiltration, and irregular fibrosis, accompanied by insufficient pancreatic exocrine, endocrine function and clinically by chronic abdominal pain, diabetes, maldigestion, malnutrition and even pancreatic cancer.The proposed pancreas regeneration mechanisms have included ductal progenitors, acinar transdifferentiation, circulating progenitors, and putative pancreatic stem cells (Granger and Kushner, 2009; Pittenger et al., 2009). Bone marrow (BM) harbors a pool of stem cells capable of differentiating into multiple tissue types. Bone marrow-derived cells have the potential to transdifferentiate into multiple lineage cells. With their regenerative potential and immunoregulatory effect, MSC therapy is a promising tool in the treatment of degenerative, inflammatory, and autoimmune diseases, including chronic pancreatitis.

\section{Histopathology of chronic pancreatitis}

Chronic pancreatitis $(\mathrm{CP})$ is a progressive fibroinflammatory disorder of the pancreas characterized pathologically by fibrosis and permanent destruction of acinar cells. Although the etiologies of CP may differ, the histologic features of the disease are similar. The key histopathologic features of $\mathrm{CP}$ are pancreatic fibrosis, acinar atrophy, chronic inflammation, and distorted and blocked ducts. In sequential fashion, variable interlobular, lobular, and ductal fibrosis may be seen throughout the gland in the early stages of CP and become more diffuse as the disease progresses. As acinar cells within the lobules are destroyed by fibrosis, exocrine dysfunction ensues. The islets of Langerhans are generally preserved until $\mathrm{CP}$ is advanced, and endocrine dysfunction generally lags behind that of the exocrine pancreas. In advanced stages, subintimal fibrosis of blood vessels can be demonstrated and nerve fibers are drawn into the fibrotic process. Infiltrating into these areas of fibrosis are lymphocytes, plasma cells, and macrophages. 
Pancreatic stellate cells (PSCs) play a key role in pancreatic fibrosis. The PSC has been demonstrated in vitro and in vivo to be primarily involved with collagen deposition and eventual fibrosis. PSCs are activated by cytokines released from infiltrating leucocytes and the injured acinar cells. The end stage of chronic pancreatitis is identified by loss of all secretory tissue, disappearance of inflammatory cells, and intense fibrosis. This progression resembles that from chronic active hepatitis to liver cirrhosis. Additional distinctive histologic features have been described in some forms of $\mathrm{CP}$, such as extensive pancreatic calcification in tropical pancreatitis and a prominent lymphocytic and plasma cell infiltrate in autoimmune pancreatitis.

\section{The mechanisms of pancreas self-renew}

How does the injured pancreas self-renew ? Where do the cells involving the pancreatic regeneration and self-renewing come from? These are the questions have not been clarified for a long time. Pancreas regeneration has been studied for more than 30 years and until now, the search for specific pancreatic stem cells has focused on pancreatic ductular cells, pre-existing $\beta$ cells, and embryonic stem cells.

Pancreatic ductal cell lines and primary ductal cells have been successfully differentiated into insulin-expressing cells by in vitro approaches, including treatment with growth factors (e.g., EGF, Gastrin, exendin), expression of pancreatic transcription factors, and aggregation (Xia et al, 2009; Hanley et al, 2008; Weir et al, 2000,2002,2009). Neogenesis of insulinproducing cells from differentiated pancreatic ductal cells results from their dedifferentiation into progenitors, expressing markers like PDX1 (Pancreatic and duodenal homeobox 1), which redifferentiate into insulin-producing and other pancreatic cells. Hence, "terminally" differentiated ductal cells can be considered facultative stem cells. Like ductal cells, lineage-marked acinar cells in response to EGF underwent in vitro differentiation into insulin expressing cells (Minami et al.,2005). A role for acinar-to-ductal transdifferentiation has also been suggested in conversion of acinar cells into endocrine cells. These observations demonstrate that multiple cell sources can differentiate into insulin-producing cells under in vitro culture conditions.

Animal models in which pancreatic endocrine and exocrine regeneration can be observed include chemically induced models of pancreatic injury following administration of alloxan (Davidson et al.,1989; Waguri et al.,1997), streptozotocin (Like \& Rossini, 1976) or caerulein (Elsasser et al., 1986), dietary copper deprivation (Abdullah et al.,2000), physical disruption of pancreatic duct function by cellophane wrapping of the organ (Wolf-Coote et al., 1996; Rafaeloff et al., 1997)or ligation of the pancreatic duct, hemipancreatectomy (Weir et al.,1993; Sharma et al., 1999 ) and local over-expression of Reg1 (Yamaoka et al., 2000), IFNY (Kritzik et al.,1999; Gu et al., 1997) or TGF-a (Sandgren et al., 1990). Although the triggers may differ, in each of these models pancreatic regeneration is thought to occur through the expansion of progenitor cells present either in, or closely associatedwith, the ductal epithelium. In these models, both endocrine and exocrine cells have been observed to arise from duct cells. Supporting this observation, 'transitional' cells have been identified that co-express ductal markers with endocrine or exocrine cell-specific markers, suggesting a reprogramming of duct-like cells (Gu et al., 1993,1994; Wang et al.,1995). 
In many of these models of regeneration, there is a striking proliferation of ductal epithelia and newly formed ductal complexes. In the $90 \%$ pancreatectomy model, regeneration has been suggested to mimic embryonic pancreogenesis with proliferation occurring initially from expansion of the common pancreatic duct epithelium followed by branching of smaller ductules and subsequent regeneration of exocrine, endocrine and mature duct cells (Weir et al.,1993). In contrast, in models of exocrine pancreatic injury, ductal proliferation has been ascribed to condensation of the existing ductular network (Kelly et al.,1999), dedifferentiation of acinar cells to duct-like cells, or, as in the pancreatectomy model, to proliferation of the ductal epithelia. In summary, models of pancreas regeneration reveal that islet and acinar regeneration occur proximate to ductal tissue.

Acinar and endocrine cells probably have a similar epigenetic profile as they share a common multipotent progenitor, which should make transdifferentiation of acinar cells into $\beta$-cells easier than from non-pancreatic cells (Gu et al.,2003).

In the adult pancreas, acinar cell growth is influenced by hormonal stimulation, notably by the gut hormone cholecystokinin (CCK). It is reported that CCK induces adaptive acinar cell growth by causing nuclear translocation of nuclear factor of activated Tcells (NFAT) via the $\mathrm{Ca}^{2+} /$ calmodulin-dependent phosphatase calcineurin (Gurda et al.,2008). In response to injury, the pancreas activates regenerative processes to maintain tissue homeostasis. The prevailing notion is that after injury, acinar cells might dedifferentiate into a ductal epithelium that expresses early developmental factors. These 'facultative progenitor cells' would then redifferentiate into mature acinar cells. Two recent reports highlight the importance of the expression of embryonic factors by acinar cells in guiding the regenerative process. It is showed that reactivation of the Notch signaling pathway during injury from caerulein-induced pancreatitis is required for acinar cell regeneration (Siveke et al., 2008). Fendrich et al. found that embryonic signaling by Hedgehog was upregulated in acinar cells after caerulein-induced pancreatitis, and that its blockade either pharmacologically or genetically, using PDX1 or elastase-Cre recombinase, allowed the formation of a ductal epithelium from acinar cells, but it did not permit the redifferentiation into acini (Fendrich et al., 2008). Intriguingly, the authors suggest that the 'redifferentiation arrest' might provide a link between pancreatitis injury and subsequent neoplasia. The results also underscore the capacity of the acinar cell to revert to an earlier progenitor state in response to injury.

Recent findings suggest that pancreatic progenitor cells might not be limited to the pancreas, but that cells from other tissues could be mobilized and induced to differentiate and contribute to the regenerative process. Stimuli such as surgical removal of a part of the pancreas, cellophane wrapping and transplantation of bone marrow cells can induce pancreatic regeneration to different extents.

Advances in defining the molecular basis of early pancreogenesis have contributed to an understanding of the process of regeneration that occurs in animal models of pancreatic injury and diabetes. However, pancreatic progenitor cell populations remain poorly defined and the subject of considerable debate (Andrew et al., 2004).

The question remains open whether a pluripotent pancreatic progenitor cell exists or whether duct associated regeneration reflects the inherent plasticity of these cells. GLUT-2 (glucose transporter 2) has been reported to be a potential marker of progenitor cells because it is induced in ductal or islet cells in models of regeneration. 
In suspension culture, rat acini lose their exocrine phenotype and express the duct-cell markers cytokeratin (CK)-7 and CK-20 coincident with PDX1, Ptf1a and Flk1. The continued expression of Ptf1a and the induction of PDX1 and Flk1 in these cells is particularly intriguing given that both PDX1 and Ptf1a are markers of early pancreatic progenitors and that the ligand of Flk1, VEGF has been implicated in early pancreogenesis and endocrine development. The induced expression of genes such as PDX1, GLUT-2, Flk1 and Kuz during pancreas regeneration is particularly interesting as it is clearly reminiscent of embryonic gene expression programs. This recapitulation of embryonic phenotype is a common theme in many of the animal models of regeneration and is indicative of the presence of progenitor cells in the adult pancreas (O'Reilly et al., 1997; Song et al., 1999).

An important feature of epithelial cells is their ability to continuously regenerate. This process, in the adult, is limited to different degrees in different epithelial organs by the rate of cell division. For example, epidermal keratinocytes and intestinal cells have a rapid turnover, whereas pancreatic epithelial cells replicate slowly.

The existence of organ-specific adult stem cells is now widely accepted. However, it is clear that somatic adult stem cells are rare and therefore difficult to isolate and study. They reside in a microenvironment or niche (Schofield et al., 1978), within which they are closely associated with tissue stromal cells and daughter cells, which controls and determines their fate. Identifying the presumptive pancreatic stem cell niche and defining the cellular and molecular components that regulate pancreas specific developmental programmes remains the subject of intensive research.

\section{Properties and immunosuppressive activity of MSCs}

Mesenchymal stem cells (MSCs) are non-hematopoietic cells with multi-lineage potential (Barry \&Murphy,2004). They have been shown to differentiate into various tissues of mesodermal origin, such as adipocytes, osteoblasts, chondrocytes, tenocytes, and skeletal myocytes. They can be isolated from bone marrow (BM) and various other sources such as umbilical cord blood or adipose tissues and have the capacity to extensively proliferate in vitro. Their capacity to differentiate into various lineages and their in vitro proliferative potential makes them attractive targets for regenerative medicine applications.

It has been demonstrated that MSCs possess immunomodulatory properties. MSCs are shown to inhibit $\mathrm{T}$ cell proliferation and to influence the maturation and expression profile of professional antigen presenting cells such as dendritic cells (DCs). For instance, MSCs from various species (humans, rodents and primates) can suppress the response of $\mathrm{T}$ cells to mitogenic and polyclonal stimuli and to their cognate peptide. Such an effect is not cognate dependent because it can still be observed using MSCs from third-party donors fully mismatched for the MHC haplotype of the responder $\mathrm{T}$ cells or MSCs which are constitutively negative for MHC molecule expression. MSC-induced unresponsiveness lacks any selectivity, as it similarly affects memory and naïve $\mathrm{T}$ cells as well as CD4 ${ }^{+}$and $\mathrm{CD} 8^{+}$ subsets.

The characterisation of MSC-induced anergic T cells showed that the inhibitory effect of MSCs is directed mainly at the level of T cell proliferation. T cells stimulated in the presence of MSCs are arrested at the G1 phase as a result of cyclin D2 downregulation. The expression of CD25 and CD69 markers of T cell activation is completely unaffected by MSC co-culture, and 
inhibition of T cell effector functions can be reversed by MSCs removal. Whilst MSCs induce an unresponsive $\mathrm{T}$ cell profile, they can prevent the apoptosis of activated $\mathrm{T}$ cells, indicating that MSC-mediated immunosuppression results from an induced division arrest anergy.

The effects of MSCs on immune responses are not confined to T cells. Although they are susceptible to recognition and lysis by IL-2 activated cells and natural killer (NK) cells in vitro, due to their low expression of HLA class I, MSCs have been demonstrated to be capable of inhibiting the proliferation of interleukin-2 (IL-2) or IL-15 stimulated NK cells. Whilst there is agreement on the immunosuppressive ability of MSCs on NK cells, their influence on NK cell-mediated cytotoxicity remains controversial. Initial data suggested that MSC s could inhibit the cytolytic activity of IL-2 activated NK cells, but more recent studies have shown that lysis of HLA I positive allogeneic targets by freshly isolated NK cells is not inhibited by MSCs. NK cells' cytokine production is also influenced by MSCs, which are able to induce the release of IFN-yand TNF-a.

The effect of MSCs on B cell proliferation remains controversial. Studies in the mouse and humans showed that MSCs inhibit B cell proliferation, inducing a block in G0/G1 phase of the cell cycle. MSCs have also been shown to inhibit the differentiation of B cells to antibody secreting cells as well as downregulating CXCR4, CXCR5 and CCR7 chemokine receptors. In contrast, other studies have suggested that human MSCs promote the proliferation and differentiation of B cells from healthy donors and patients with systemic lupus erythematosus. Although apparently in contradiction, the opposing results of these studies can be reconciled by the different conditions in which B cells have been stimulated. As a result of different B cell stimulation, the secreted cytokines could in fact polarise MSC towards a proinflammatory phenotype. This concept is well established for other cell types with regulatory functions, such as monocytes/macrophages.

Considering their regenerative potential and immunoregulatory effect, MSC-therapy is a promising tool in the treatment of degenerative, inflammatory, and autoimmune diseases. However, the current understanding from results of clinical trials is that MSC-therapy is safe but its therapeutic efficiency needs to be improved (Trento \& Dazzi, 2010).

\section{Experimental study of MSCs on chronic pancreatitis}

One additional and crucial feature of MSCs is their ability to selectively migrate to sites of injury. However, the use of MSCs in pancreatic regeneration is just now emerging.

With above-mentioned provocative in vitro and in vivo observations, we sought to observe the protective properties and to explore the potential mechanism of the BMSCs in treating $\mathrm{CP}$ rat model. Our study demonstrated that BMSCs in rats caused (1) an intensified and much higher GFP (green fluorescent proteins) fluorescence expression of positive GFPlabeled cells in the pancreatic tissue of model plus BMSCs $\left(\mathrm{GFP}^{+}\right)$group compared with that of the control group (Fig 3) ; (2) a marked attenuation of pancreatic pathological injury and fibrosis of BMSCs treated group compared to those of model group (Fig 2; Fig 4; Table 1);(3) a significant reduction of pancreatic CTGF, TGF- $\beta$, type-I collagen, type-III collagen and MPO activities(Table 2). Our findings suggest that BMSCs have obvious therapeutic effects in the treatment of $\mathrm{CP}$, which may be related to their recruitments to the damaged pancreatic tissue as seeds cells and their inhibition of CTGF,TGF- $\beta$ release by autocrine or paracrine effects, thus decreasing the type-I collagen, type-III collagen and MPO producing. 
In our study, it was revealed that BMSCs only recruited to the injured pancreas. In the sham plus BMSCs $\left(\mathrm{GFP}^{+}\right)$group, although BMSCs $\left(\mathrm{GFP}^{+}\right)$were transplanted to the rats as model plus BMSCs $\left(\mathrm{GFP}^{+}\right)$group, the GFP fluorescence was still absent in the pancreas tissue(Fig 3). As for the mechanism of BMSCs homing to the injured pancreas, a growing number of studies of various pathologic conditions have demonstrated that MSC selectively home to sites of injury, irrespective of the tissue. Homing involves a cascade of processes initiated by shear resistant adhesive interactions between flowing cells and the vascular endothelium at target tissue. This process is mediated by 'homing receptors' expressed on circulating cells that engage relevant endothelial co-receptors, resulting in cell-tethering and rolling contacts on the endothelial surface. This is typically followed by chemokine triggered activation of integrin adhesiveness, firm adhesion and extravasation.

Therefore, we may deduce the mechanisms of MSCs treating CP as followed three points. The first one is that MSCs can recruit to and reside in the injured pancreas as the "seed cells", also they can differentiate into the pancreatic "target cells" or "functional cells" such as acinar cells, Islet(like) cells, ductal cells and pancreatic stem cells, etc. Second, MSCs exert their regenerating effects through the paracrine/autocrine function, secreting many kinds of bioactive molecules (such as stem cell growth factor, SCGF), antagonizing the effects of proinflammatory cytokines, alleviating the pathological injury, inhibiting the proliferation of the pancreatic stellate cells. The latter is that MSCs can ameliorate the immune-inflammatory injury within the pancreas by their immunosuppressive and immunoregulatory functions which include inhibiting the T lymphocytes, cyto-toxic T lymphocytes, NK cells, macrophages and mast cells. However, the details of the mechanisms abovementioned remain an active area of investigation.

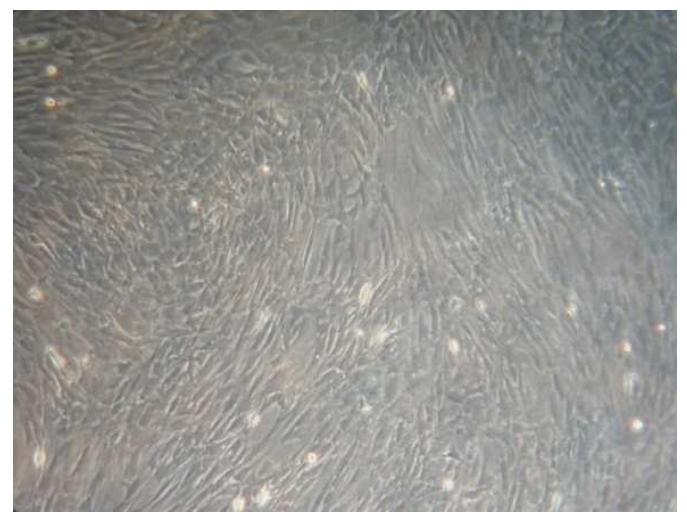

Fig. 1. Subcultured BMSCs in vitro. Phase contrast micrograph of mesenchymal stem cells cultured on day seven passage $2(40 \times)$. Rat BMSCs were successfully isolated from bone marrow via gradient centrifugation, expanded in monolayer culture. Most of the nonadherent cells were removed during the first media change at $24 \mathrm{~h}$. Three days after culture, the BMSCs began to stretch. Colonies of fibroblast-like cells attached to the plastic were evident at day 4-5 after initial seeding. Cell colonies were formed and number of adherent cells increased rapidly, BMSCs reached $80-90 \%$ of confluence by 12 day and arranged regularly in the swirl shape. 


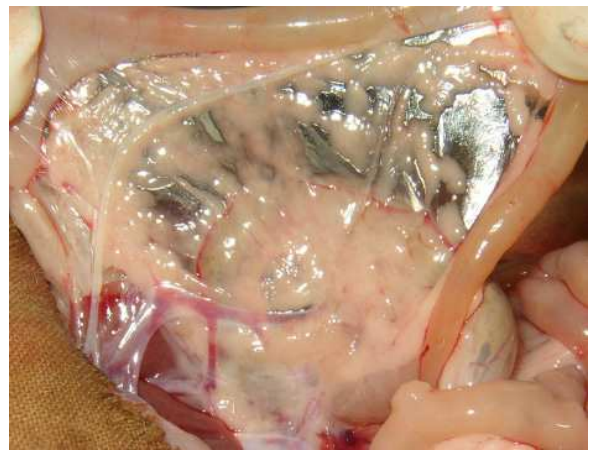

(a) Sham plus BMSCs $\left(\mathrm{GFP}^{+}\right)$

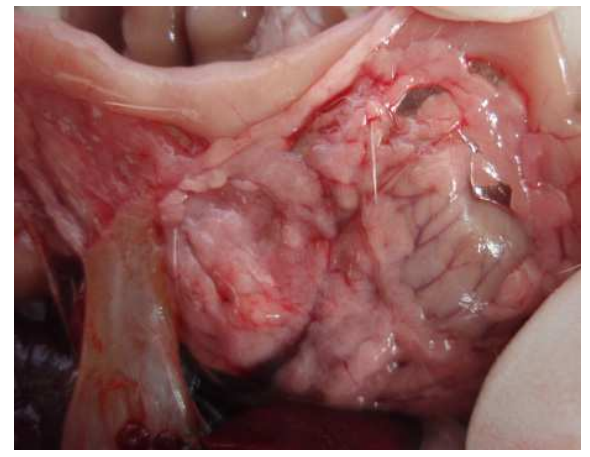

(b) Chronic pancreatitis model

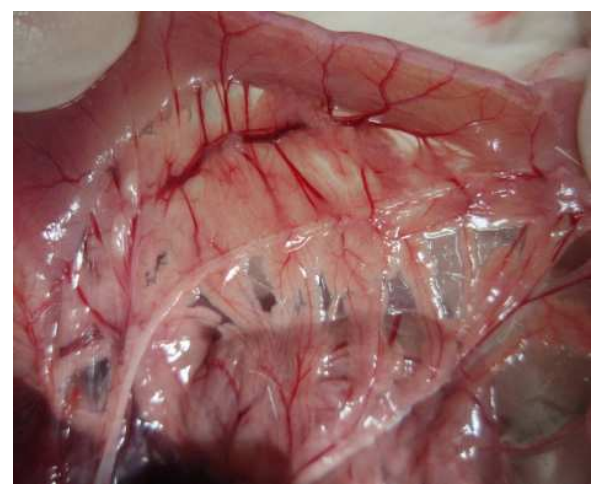

(c) Model plus BMSCs(GFP+)

Fig. 2. Gross appearance of pancreas tissue in sham plus BMSCs $\left(G^{+} P^{+}\right)(a)$, model (b) and model plus BMSCs $\left(\mathrm{GFP}^{+}\right)$groups (c). a and c, pancreas has an intact appearance. $b$, note the scattered thickening, swelling foci and markedly dilated biliopancreatic duct.

\begin{tabular}{lcll}
\hline & $\mathrm{n}$ & Histologic score & Fibrosis score \\
\hline sham+BMSCs $\left(\mathrm{GFP}^{+}\right)$ & 10 & 0 & 0 \\
model & 10 & $7.92 \pm 2.58^{*}$ & $1.98 \pm 0.57^{*}$ \\
model+BMSCs $\left(\mathrm{GFP}^{+}\right)$ & 10 & $2.17 \pm 0.37 \#$ & $0.38 \pm 0.09 \#$ \\
\hline
\end{tabular}

${ }^{*} \mathrm{P}<0.001$ vs sham $+\mathrm{BMSC}\left(\mathrm{GFP}^{+}\right)$group. $\#+\mathrm{P}<0.01$ vs model group

Table 1. Histopathologic and fibrosis scores of pancreas tissue in all groups (mean \pm SD) 


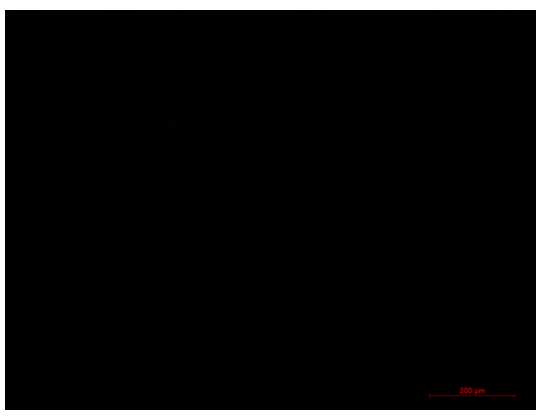

(a) Sham plus BMSCs (GFP+)

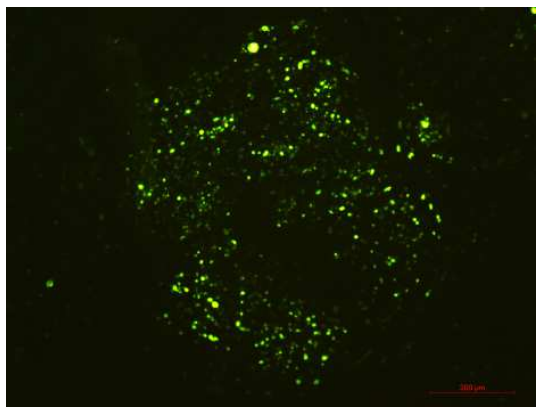

(c) Model plus BMSCs(GFP+) (low magnification)

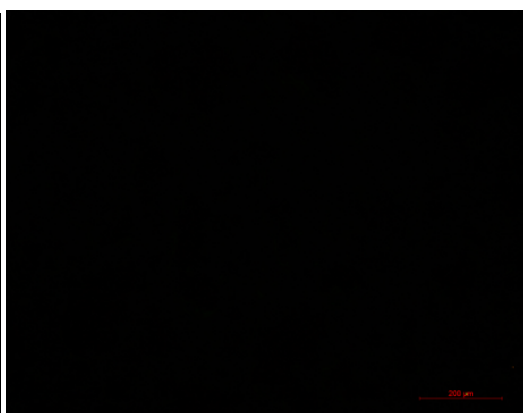

(b) Chronic pancreatitis mode

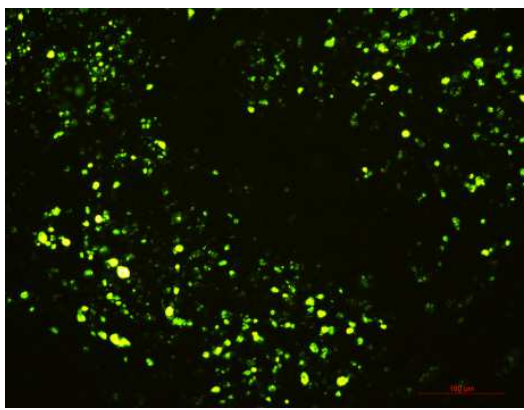

(d) Model plus BMSCs(GFP+) (medium magnification)

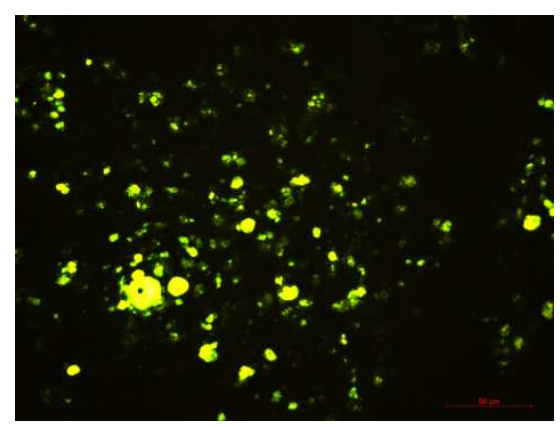

(e) Model plus BMSCs(GFP+)

(high magnification)

Fig. 3. GFP+-BMSCs in the frozen pancreatic sections. No positive green fluorescence appeared in the pancreatic sections of sham plus BMSCs (GFP+) group (a), model (b).GFP signals were clearly observed in pancreas from frozen sections after GFP+-BMSCs transplantation of model plus BMSCs $\left(\mathrm{GFP}^{+}\right)$group examined in fluorescence microscopy(c, low magnification; $d$, medium magnification; $e$, high magnification). 


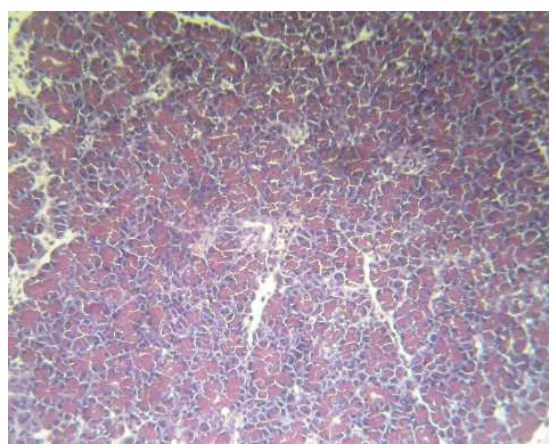

(a) Sham plus BMSCs (GFP+)

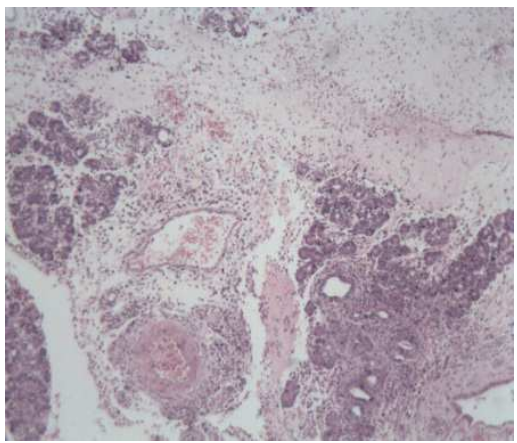

(b) Chronic pancreatitis mode

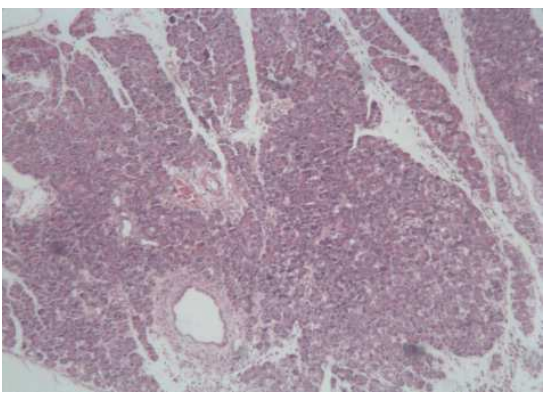

(c) Model plus BMSCs(GFP+)

Fig. 4. Representative light microscopic appearances of the pancreas stained with hematoxylin and eosin (H\&E). a. In sham plus BMSCs (GFP+) group, no alteration was observed. b. In model group, massive infiltration of inflammatory cells, with disappearance of acinar cells are evident. c. In model plus BMSCs (GFP+) group, the distribution of fibrosis and inflammatory cells were markedly attenuated and acinar cells and lobular architecture can be seen.

\begin{tabular}{lcccccc}
\hline & $\mathrm{n}$ & $\begin{array}{c}\text { CTGF } \\
\text { (pg/ mg } \\
\text { prot) }\end{array}$ & $\begin{array}{c}\text { TGF- } \beta \\
\text { (pg/ mg } \\
\text { prot })\end{array}$ & $\begin{array}{c}\text { collagen I } \\
\text { (pg/ mg } \\
\text { prot })\end{array}$ & $\begin{array}{c}\text { collagen III } \\
\text { (ng/ mg } \\
\text { prot })\end{array}$ & $\begin{array}{c}\text { MPO } \\
\text { (mU/mg prot) }\end{array}$ \\
\hline $\begin{array}{l}\text { sham+BMSCs } \\
\left(\mathrm{GFP}^{+}\right)\end{array}$ & 10 & $19.8 \pm 9.8$ & $10.1 \pm 2.9$ & $60.9 \pm 15.1$ & $18.4 \pm 6.2$ & $0.41 \pm 0.14$ \\
$\begin{array}{l}\text { model } \\
\text { model+BMSCs }\end{array}$ & 10 & $279.8 \pm 20.8^{*}$ & $58.7 \pm 9.1^{*}$ & $245.7 \pm 35.8^{*}$ & $73.1 \pm 10.4^{*}$ & $2.75 \pm 0.47$ \\
\begin{tabular}{l}
$\left(\mathrm{GFP}^{+}\right)$ \\
\hline
\end{tabular} & $121.4 \pm 20.1 \#$ & $18.9 \pm 4.7 \#$ & $142.9 \pm 28.5 \#$ & $35.8 \pm 10.1 \#$ & $1.12 \pm 0.18$ \\
\hline
\end{tabular}

${ }^{*} \mathrm{P}<0.001$ vs sham $+\mathrm{BMSC}$ (GFP+) group. \# $+\mathrm{P}<0.01$ vs model group

Table 2. Pancreatic CTGF, TGF- $\beta$, collagen I, collagen III and MPO contents in all groups (mean \pm SD) 


\section{Safety issues}

The first clinical trials with adult stem/ progenitor cells to repair non-haematopoietic tissues were carried out with MSCs (Prockop et al., 2007). The initial clinical trials with MSCs were in osteogenesis imperfecta patients (Horwitz et al.,2001) and in patients suffering mucopolysaccharidoses (Koc et al.,2002). Other indications for which clinical trials using MSCs have been initiated are suppression of GVHD severe autoimmune diseases, repair of skeletal tissue, amyotrophic lateral sclerosis, chronic spinal cord injury, non-healing chronic wounds, vascular disease, coronary artery disease and myocardial infarction. Currently, the largest number of clinical trials is in patients with heart disease with MSCs.

As of this writing, more than 100 clinical trials involving MSCs transplantation have been registered with the US Food and Drug Administration (www.clinicaltrials.gov). While most of the studies are currently ongoing or are small Phase I and Phase II safety trials, current findings suggest that MSCs transplants are safe and offer no suggestion of malignancy risk.

Currently, bone marrow, subcutaneous adipose tissue and umbilical cord blood are among the main sources for isolating MSCs. Human trials of MSCs transplantation are roughly evenly divided between the use of autologous and allogeneic cells and these trials employ both freshly-isolated and ex-vivo culture expanded cell populations. While most MSCs used for transplant are derived from BM, cells isolated from adipose, umbilical cord, and other MSC sources such as peripheral blood liver are being employed. These clinical trials employ MSCs for a multitude of different purposes in different disease states, including tissue replacement in musculoskeletal, cardiac and liver diseases, and as immunomodulatory cells to mitigate GVHD, organ transplant rejection and autoimmune disorders.

The main potential risks might paradoxically centre on the exquisite ability of MSCs to suppress immune responses, which may promote a state of immune deficiency leading to infection or activation of benign tumours (Djouad et al., 2003). Another concern is whether administered MSCs promote the growth of a latent tumor. MSC can be recruited to the stroma of developing tumors when systemically infused in animal models for glioma, colon carcinoma, ovarian carcinoma, Karposi's sarcoma and melanoma. Other detrimental effects might involve the ability of MSCs to migrate to tumours, which could lead to reciprocal interactions between MSCs and malignant cells thus promoting tumour growth and metastasis (Karnoub et al.,2007). A further tumourigenic risk may be associated with extensive in vitro culture of MSCs, which has been shown to initiate cytogenetic abnormalities and subsequent tumour formation upon transplantation in murine hosts. However, there is increasing evidence that with respect to the risk of MSCs transformation and subsequent tumor formation initiated by MSCs, human MSCs appear to be safe. Therefore we feel impelled to strongly recommend at this point careful quality control procedures for all cell preparations. These should be implemented for all kinds of cell-based therapies. Suffice it to say that before administering MSCs to patients the cell preparations have to undergo careful phenotypic, functional, and genetic characterizations.

In conclusion, the record of safety for MSCs in general is excellent and we anticipate that after successful conclusion of ongoing preclinical and clinical tests, MSCs will be gradually introduced into clinical practice for a number of disease conditions in the coming years. Careful pre-administration safety monitoring as well as close monitoring of the patients are important pre-requisites for the success of this novel form of therapy. Regulatory bodies such as the US Food and Drug administration and the European Union have recently established a set of regulations for cell-based therapeutics. With continuous and open interactions between 
investigators, research institutions and regulatory bodies, successful, and most importantly, safe cell-based therapies will become routine for patients' treatment in the near future.

\section{Acknowledgment}

The authors gratefully acknowledge the expert technical assistance provided by Fan-Ming Kong, Xiao-Ping Xue, and Xiu-Zhu Yang

\section{References}

Al-Abdullah IH, Ayala T, Panigrahi D, Kumar RM, Kumar MS(2000). Neogenesis of pancreatic endocrine cells in copper-deprived rat models. Pancreas; 21: 63-68.

Barry FP, Murphy JM(2004). Mesenchymal stem cells: clinical applications and biological characterization. Int J Biochem Cell Biol; 36:568-84.

Bonner-Weir S, Taneja M, Weir GC, et al(2000). In vitro cultivation of human islets from expanded ductal tissue. ProcNatlAcadSciUSA;97:7999-8004.

Bonner-Weir S, Sharma A(2002). Pancreatic stem cells. J Pathol;197(4):519-26.

Bonner-Weir S, Baxter LA, Schuppin GT, Smith FE(1993). A second pathway for regeneration of adult exocrine and endocrine pancreas. A possible recapitulation of embryonic development. Diabetes; 42: 1715-1720.

Davidson PM, Campbell IL, Oxbrow L, Hutson JM, HarrisonLC(1989). Pancreatic beta cell proliferation in rabbits demonstrated by bromodeoxyuridine labeling. Pancreas, 4:594-600.

Djouad, F., Plence, P., Bony, C., et al. (2003). Immunosuppressive effect of mesnechymal stem cells favors tumor growth in allogeneic animals. Blood, 102, 3837-3844.

Elsasser HP, Adler G, Kern HF(1986). Time course and cellular source of pancreatic regeneration following acute pancreatitis in the rat. Pancreas; 1: 421-429.

Fendrich V, Esni F, Garay MV, et al(2008). Hedgehog signaling is required for effective regeneration of exocrine pancreas. Gastroenterology;135:621-631.

Granger, A., and Kushner, J.A. (2009). Ductal Origin Hypothesis of Pancreatic Regeneration under Attack. J. Intern. Med. 266, 325-338.

$\mathrm{Gu}$ D, Sarvetnick N(1993). Epithelial cell proliferation and islet neogenesis in IFN-g transgenic mice. Development; 118:33-46.

Gu D, Lee MS, Krahl T, Sarvetnick N(1994). Transitional cells in the regenerating pancreas. Development; 120: 1873-1881.

Gu D, Arnush M, Sarvetnick N(1997). Endocrine/exocrine intermediate cells in streptozotocin-treated Ins-IFN- gamma transgenic mice. Pancreas; 15: 246-250.

Gu G, Brown JR, Melton DA( 2003). Direct lineage tracing reveals the ontogeny of pancreatic cell fates during mouse embryogenesis. Mech Dev;120(1):35-43.

Gurda GT, Guo L, Lee SH, et al(2008). Cholecystokinin activates pancreatic calcineurinNFAT signaling in vitro and in vivo. Mol Biol Cell;19:198-206.

Hanley NA, Hanley KP, Miettinen PJ, et al(2008). Weighing up beta-cell mass in mice and humans: selfrenewal, progenitors or stem cells? Mol Cell Endocrinol;288(12):79-85.

Holland A M., LJ G'o nez \& Leonard C. Harrison(2004).Progenitor cells in the adult pancreas. Diabetes Metab Res Rev; 20: 13-27.

Horwitz EM, Prockop DJ, Gordon PL, Koo WWK, Fitzpatrick LA, Neel MD, McCarville ME, Orchard PJ, Pyeritz RE, Brenner MK( 2001). Clinical responses to bone marrow transplantation in children with severe osteogenesis imperfecta. Blood, 97:1227-1231. 
Karnoub, A. E., Dash, A. B., Vo, A. P., et al. (2007).Mesenchymal stem cells within tumour stroma promote breast cancer metastasis. Nature, 449, 557-563.

Kelly L, Reid L, Walker NI(1999). Massive acinar cell apoptosis with secondary necrosis, origin of ducts in atrophic lobules and failure to regenerate in cyanohydroxybutene pancreatopathy in rats. Int J Exp Pathol; 80: 217-226.

Koc ON, Day J, Nieder M, Gerson SL, Lazarus HM, Krivit W(2002). Allogeneic mesenchymal stem cell infusion for treatment of metachromatic leukodystrophy (MLD) and Hurler syndrome (MPS-IH). Bone Marrow Transplantation;30:215-222.

Kritzik MR, Jones E, Chen Z, et al(1999). PDX-1 and Msx-2 expression in the regenerating and developing pancreas. J Endocrinol; 163: 523-530.

Like AA, Rossini AA(1976). Streptozotocin-induced pancreatic insulitis: new model of diabetes mellitus. Science; 193:415-417.

Minami K, Okuno M, Miyawaki K, et al(2005). Lineage tracing and characterization of insulin-secreting cells generated from adult pancreatic acinar cells. Proc Natl Acad Sci U S A, 102(42):15116-21.

O'Reilly LA, Gu D, Sarvetnick N, et al(1997). Alpha-Cell neogenesis in an animal model of IDDM. Diabetes; 46: 599-606.

Pittenger, G.L., Taylor-Fishwick, D., and Vinik, A.I. (2009). A role for islet neogenesis in curing diabetes. Diabetologia, 52(5):735-8.

Prockop DJ, Olson SD(2007). Clinical trials with adult stem/progenitor cells for tissue repair: Let's not overlook some essential precautions. Blood,109:3147-3151.

Rafaeloff R, Pittenger GL, Barlow SW, et al (1997). Cloning and sequencing of the pancreatic islet neogenesis associated protein (INGAP) gene and its expression in islet neogenesis in hamsters. J Clin Invest; 99: 2100-2109.

Sandgren EP, Luetteke NC, Palmiter RD, Brinster RL, Lee DC(1990). Overexpression of TGF alpha in transgenic mice: induction of epithelial hyperplasia, pancreatic metaplasia, and carcinoma of the breast. Cell; 61: 1121-1135.

Schofield R(1978). The relationship between the spleen colonyforming cell and the haemopoietic stem cell. Blood Cells;4: 7-25.

Sharma A, Zangen DH, Reitz P, et al( 1999). The homeodomain protein IDX-1 increases after an early burst of proliferation during pancreatic regeneration. Diabetes; 48: 507-513.

Siveke JT, Lubeseder-Martellato C, Lee M, et al(2008). Notch signaling is required for exocrine regeneration after acute pancreatitis. Gastroenterology;134:544-555.

Song SY, Gannon M,Washington MK, et al(1999). Expansion of Pdx1-expressing pancreatic epithelium and islet neogenesis in transgenic mice overexpressing transforming growth factor alpha. Gastroenterology; 117: 1416-1426.

Trento C, Dazzi F (2010). Mesenchymal stem cells and innate tolerance: biology and clinical applications. Swiss Med Wkly.;140:w13121

Waguri M, Yamamoto K, Miyagawa JI, et al(1997). Demonstration of two different processes of beta-cell regeneration in a new diabetic mousemodel induced by selective perfusion of alloxan. Diabetes; 46: 1281-1290.

Wang RN, Kloppel G, Bouwens L(1995). Duct- to islet-cell differentiation and islet growth in the pancreas of duct-ligated adult rats. Diabetologia; 38: 1405-1411.

Wolfe-Coote S, Louw J, Woodroof C, Du Toit DF (1996). The non-human primate endocrine pancreas: development, regeneration potential and metaplasia. Cell Biol Int; 20:95-101.

Xia B, Zhan XR, Yi R, et al(2009). Can pancreatic duct-derived progenitors be a source of islet regeneration? Biochem Biophys Res Commun;383(4):383-385.

Yamaoka T, Yoshino K, Yamada T, et al (2000). Diabetes and tumor formation in transgenic mice expressing reg I. Biochem Biophys Res Commun; 278: 368-376. 


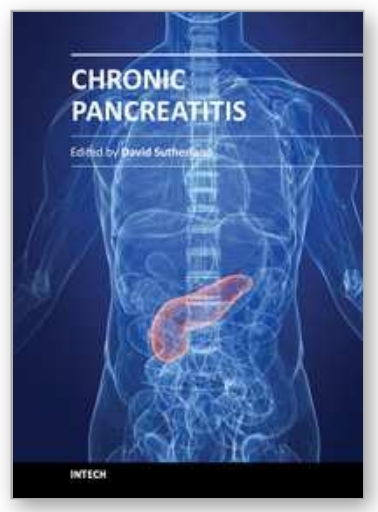

\author{
Chronic Pancreatitis \\ Edited by Prof. David Sutherland
}

ISBN 978-953-51-0011-9

Hard cover, 138 pages

Publisher InTech

Published online 15, February, 2012

Published in print edition February, 2012

Chronic pancreatitis is a disease of diverse etiologies in which pain can be devastating, severely impairing quality of life, and treatment is a challenge. This book covers cutting edge basic science research and clinical diagnosis and treatment issues in chronic pancreatitis. Basic science chapters include studies on amelioration of chronic pancreatitis in rats by bone marrow derived mesenchymal cells; on gene therapy using HSVEnkephalin to reduce fibrosis, inflammation and pain in a rats; and on pancreatic acinar and island neogenesis according to vascular and matrix dynamics of human and animal tissue. In regard to the clinical aspects, the role of endoscopic ultrasound in detecting the changes of chronic pancreatitis are addressed as well as the endoscopic treatment via duct drainage procedures or stone removal. Finally, the surgical options for chronic pancreatitis (there are well over 20 procedures) are extensively discussed, with a final chapter on total pancreatectomy and islet autotransplant to definitively remove the root cause of the pain with preservation of endocrine function. This book will be valued by basic scientists and clinicians striving to understand the mechanisms of pain in chronic pancreatitis and the treatment options in patients so afflicted.

\title{
How to reference
}

In order to correctly reference this scholarly work, feel free to copy and paste the following:

Hong Bin Liu (2012). Bone Marrow Derived Mesenchymal Stem Cells Are Recruited into Injured Pancreas and Contribute to Amelioration of the Chronic Pancreatitis in Rats, Chronic Pancreatitis, Prof. David Sutherland (Ed.), ISBN: 978-953-51-0011-9, InTech, Available from: http://www.intechopen.com/books/chronicpancreatitis/bone-marrow-derived-mesenchymal-stem-cells-are-recruited-into-injured-pancreas-andcontribute-to-ame

\section{INTECH}

open science | open minds

\section{InTech Europe}

University Campus STeP Ri

Slavka Krautzeka 83/A

51000 Rijeka, Croatia

Phone: +385 (51) 770447

Fax: +385 (51) 686166

www.intechopen.com

\section{InTech China}

Unit 405, Office Block, Hotel Equatorial Shanghai

No.65, Yan An Road (West), Shanghai, 200040, China

中国上海市延安西路65号上海国际贵都大饭店办公楼405单元

Phone: +86-21-62489820

Fax: $+86-21-62489821$ 
(C) 2012 The Author(s). Licensee IntechOpen. This is an open access article distributed under the terms of the Creative Commons Attribution 3.0 License, which permits unrestricted use, distribution, and reproduction in any medium, provided the original work is properly cited. 